\section{Primary ciliary dyskinesia: a consensus statement on diagnostic and treatment approaches in children}

\author{
A. Barbato, T. Frischer, C.E. Kuehni, D. Snijders, I. Azevedo, G. Baktai, L. Bartoloni, \\ E. Eber, A. Escribano, E. Haarman, B. Hesselmar, C. Hogg, M. Jorissen, J. Lucas, \\ K.G. Nielsen, C. O'Callaghan, H. Omran, P. Pohunek, M-P.F. Strippoli and A. Bush
}

ABSTRACT: Primary ciliary dyskinesia (PCD) is associated with abnormal ciliary structure and function, which results in retention of mucus and bacteria in the respiratory tract, leading to chronic oto-sino-pulmonary disease, situs abnormalities and abnormal sperm motility.

The diagnosis of PCD requires the presence of the characteristic clinical phenotype and either specific ultrastructural ciliary defects identified by transmission electron microscopy or evidence of abnormal ciliary function.

Although the management of children affected with PCD remains uncertain and evidence is limited, it remains important to follow-up these patients with an adequate and shared care system in order to prevent future lung damage.

This European Respiratory Society consensus statement on the management of children with PCD formulates recommendations regarding diagnostic and therapeutic approaches in order to permit a more accurate approach in these patients. Large well-designed randomised controlled trials, with clear description of patients, are required in order to improve these recommendations on diagnostic and treatment approaches in this disease.

KEYWORDS: Consensus statement, diagnosis, primary ciliary dyskinesia, treatment

\section{CONTENTS}

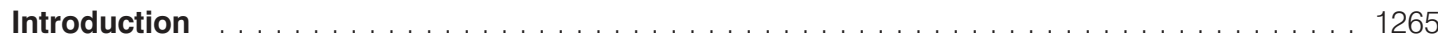

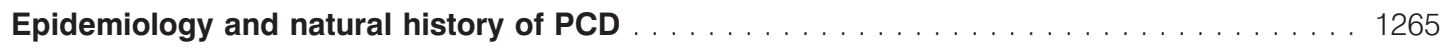

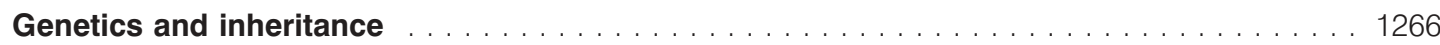

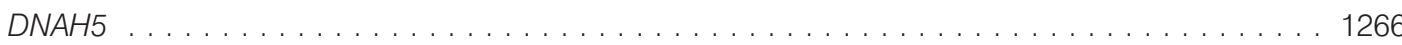

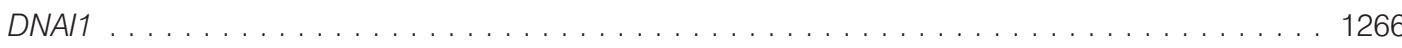

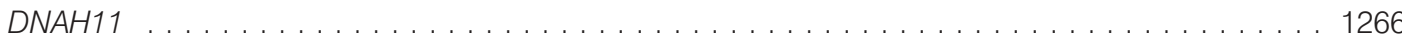

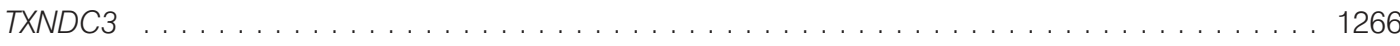

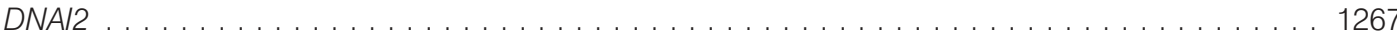

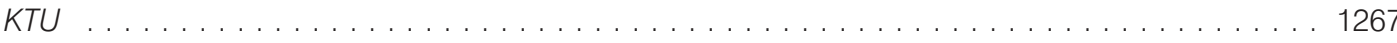

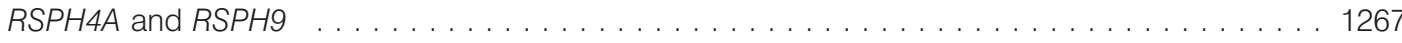

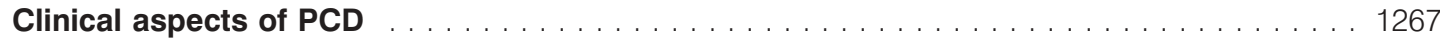

PCD as an associated diagnosis . . . . . . . . . . . . . . . . . . . . . . . . . . . 1267

Recommendations . . . . . . . . . . . . . . . . . . . . . . . . . . . . . . . . . . . 1268

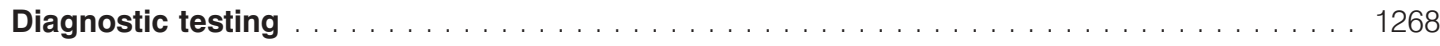

Screening tests . . . . . . . . . . . . . . . . . . . . . . . . . . . . . . . . 1269

Recommendations . . . . . . . . . . . . . . . . . . . . . . . . . . . . . . . . . . . . 1269

Diagnostic tests . . . . . . . . . . . . . . . . . . . . . . . . . . . . . . . . . . . . 1269

Obtaining a sample of ciliate cells . . . . . . . . . . . . . . . . . . . . . . . . . . . . . 1269

\section{AFFILIATIONS}

${ }^{*}$ For affiliations, please see the Acknowledgements section, and ${ }^{\#}$ All of the authors of this article were active task force members.

CORRESPONDENCE

A. Barbato

Paediatric Pulmonology Unit

Dept of Paediatrics

Via Giustiniani 3

35128 Padova

Italy

E-mail: barbato@pediatria.unipd.it

Received:

Nov 212008

Accepted after revision:

May 122009 


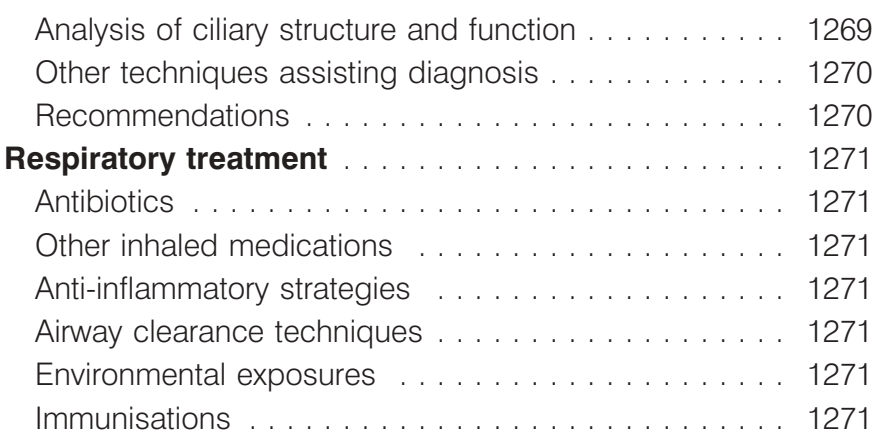

\section{INTRODUCTION}

Primary ciliary dyskinesia (PCD) is predominantly inherited as an autosomal recessive disorder leading to recurrent and chronic upper and lower respiratory tract infection, and, in 40$50 \%$ of cases, mirror-image organ arrangement and other forms of heterotaxy [1]. To date, these disorders of dysmotile cilia have been poorly studied in children; indeed most of the therapeutic strategies used are derived from cystic fibrosis (CF) protocols, underscoring the need for more PCD research. Although unproven, it seems likely that early diagnosis is important for the preservation of pulmonary function, quality of life and life expectancy in this disease, and, therefore, there is a great need for more diagnostic awareness and evidencebased treatment. Ciliary dysfunction is also implicated in a broader spectrum of disease, such as polycystic liver and kidney disease, biliary atresia and central nervous system abnormalities, including retinopathy and hydrocephalus [2].

The present consensus statement originates from a European Respiratory Society Task Force on PCD in children, which is aimed at describing diagnostic and therapeutic practices for paediatric PCD patients in Europe, assessing the number of diagnosed patients, developing a consensus statement, defining research needs and enhancing collaborative research. The Task Force included respiratory physicians skilled in paediatric PCD, ear, nose and throat (ENT) physicians, geneticists and epidemiologists from various European countries. Subgroups prepared preliminary drafts for each section, which were discussed in a plenary meeting in order to achieve consensus. The final version was revised by all of the authors. Hence this article provides the consensus statement of the Task Force members on diagnostic and therapeutic approaches to PCD in children in Europe.

In order to develop the present consensus statement, the following search strategy was utilised. Articles on aetiology, clinics, diagnosis, treatment, complications and follow-up, combined with primary ciliary dyskinesia, immotile cilia syndrome or Kartagener's syndrome, were searched separately. Articles were identified from the Cochrane Central Register of Controlled Trials (CENTRAL), PubMed, EMBASE, the list of references in relevant publications and the authors' collection of references.

Evidence levels were graded as proposed by the BMJ Clinical Evidence Grading of Recommendations, Assessment, Development and Evaluation (GRADE) Working Group [3]. The GRADE scoring system takes into account the type, quality, consistency and directness of evidence, and the size of the effect; evidence was classified as low, fair, moderate, high

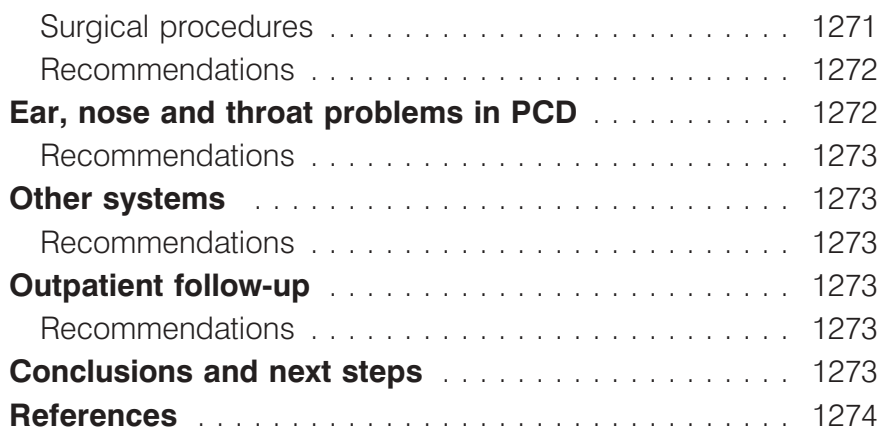

or expert opinion; benefit was described as none, conflicting, small/weak, intermediate or substantial; and strength of recommendation was classified as strong or weak. However, hardly any evidence on PCD diagnostic and treatment approaches exists, and research in children is rare, meaning that evidence levels are seldom higher than moderate, and, in some cases, research is absent. Some statements derive from CF-related studies.

\section{EPIDEMIOLOGY AND NATURAL HISTORY OF PCD}

The prevalence of PCD is very difficult to estimate accurately. In 1947 and 1949, TORGERSEN [4] published results from a radiological study involving approximately a third of the Norwegian population. It was observed that situs inversus had a prevalence of $1: 8,000$, and that $10 \%$ of those with situs inversus had bronchiectasis. Estimating the prevalence of situs inversus in PCD patients as 50\%, TORGERSEN [4] calculated the prevalence of PCD to be 1:40,000. This figure is likely to be an underestimation given the fact that standard chest radiographs are insensitive for detection of bronchiectasis, and that bronchiectasis may not be present, particularly in younger PCD patients. For Sweden, Afzelius [5] calculated an average prevalence of 1:22,000 for the years 1976-1990 by comparing the number of children with PCD known to the author with the population figures for those years. Realising the unlikelihood of knowing all cases, AfZELIUs [5] estimated the true prevalence for Sweden to be nearer to 1:10,000. In a long-term study on delayed atomic bomb effects carried out in Hiroshima and Nagasaki (both Japan), 16,566 persons underwent physical examination and chest radiography. In this very specific sample, four patients with PCD (aged 34-86 yrs) were detected, giving an estimate of 1:4,100 [6]. Considering the broad range of clinical severity in PCD and assuming that many milder cases remain undiagnosed, these latter estimates might be nearer to reality than earlier extrapolations. In clinical samples of patients with diffuse bronchiectasis, PCD is naturally more common; it might account for up to $13 \%$ of all patients with bronchiectasis, being relatively more common in North African than in European patients [7]. The mean age at diagnosis, in a paediatric case series of COREN et al. [8], was 4.4 yrs (6 yrs for those without situs inversus), which was higher than that for patients suffering from CF treated in the same clinic (1.3 yrs).

Even fewer data are available on the range of severity of symptoms and functional limitations in various age groups, and on the natural history of this disease and whether it can be influenced by treatment [8-12]. An unsatisfactory picture of longterm outcome was drawn by NoONE et al. [9] in a cross-sectional 
study during 1994-2002 of 78 subjects with PCD (including 31 children). Bronchiectasis was confirmed in $61 \%$ of the children and $98 \%$ of the adults and there was a negative association between age and loss of forced expiratory volume in $1 \mathrm{~s}$ (FEV1). The slope of the regression line plotted versus age was -0.8 (SD $0.13 \%$ ), consistent with an annual $0.8 \%$ loss of FEV1. This differs from adult CF patients in the USA, where the mean annual loss of FEV1 was reported to be $\sim 3.6 \%$. Several studies suggest that age at diagnosis, and, therefore, age at initiation of specific treatment, affects outcome. ELLERMAN and BISGAARD [10] followed 24 patients with PCD for 2-16 yrs and observed lower lung function in those patients entering the cohort as adults compared to children. All patients were treated rigorously with antibiotics and physiotherapy and maintained their lung function over the following years, suggesting that therapy offers considerable benefit. However, the data set was small and heterogeneous, and conclusions therefore questionable. In addition CORKEY et al. [11] and and HeLLINCKx et al. [12] described a relatively stable longterm progression of lung function during childhood in children treated with physiotherapy, although adolescents seemed to fare worse. A large proportion of adult patients were chronically infected with Pseudomonas aeruginosa, and 13 (27\%) out of 47 adult patients had very severe disease, with chronic respiratory failure and an FEV1 of $\leqslant 40 \%$ of the predicted value. They were all oxygen-dependent and listed for transplantation or had already received a transplant. These divergent results from different studies might be due to different inclusion criteria and patient selection. Large multicentric representative cohort studies are urgently required in order to give a clearer picture of the natural history of this disease.

\section{GENETICS AND INHERITANCE}

PCD (MIM 242650) is a genetically heterogeneous disorder, which is predominantly inherited as an autosomal recessive trait $[13,14]$. The majority of the genes identified (table 1) to date for autosomal recessive PCD variants (dynein, axonemal, intermediate chain 1 (DNAI1) and 2 (DNAI2) and heavy chain 5 (DNAH5) and 11 (DNAH11) and thioredoxin domain containing 3 (TXNDC3)) encode outer dynein arm (ODA) components [15-20], whereas only one gene (chromosome 14 open reading frame $104(K T U)$ ) is required for cytoplasmic preassembly of axonemal dyneins [21]. In addition mutations in the two genes, radial spoke head 9 homologue (RSPH9) and 4 homologue A (RSPH4A), have been reported in PCD patients with abnormalities of the central microtubular pair [22]. In a minority of cases, other inheritance patterns have been recognised [23]. Furthermore, $X$-linked recessive retinitis pigmentosa, sensory hearing deficits and PCD have been associated with mutations in the retinitis pigmentosa guanosine triphosphatase regulator gene (RPGR), essential for photoreceptor maintenance and viability [24-30]. In addition, BUDNY et al. [31] described a single family with a novel syndrome that is caused by oral-facial-digital type 1 syndrome gene (OFD1) mutations, and characterised by $\mathrm{X}$-linked recessive mental retardation, macrocephaly and PCD.

Genetic analyses may help to assess the carrier status of family members and provide tools for informed reproductive choices, although this is currently possible only for a minority of families. They may also become more important diagnostically since $\sim 35 \%$ of PCD patients carry either DNAH5 or DNAI1 mutations (hot spots and founder mutations are worthy of analysis in patients with ODA defects). Further studies are required in order to identify the genes responsible for the remaining PCD patients.

\section{DNAH5}

DNAH5 was identified using a homozygosity mapping strategy in one large inbred family with PCD and ODA defects [32]. It is the human orthologue of the Chlamydomonas $\gamma$-heavy chain gene, the mutants of which are slow-swimming algae with ultrastructural ODA defects [18, 33]. Mutations in human DNAH5 are regularly associated with ODA defects, random left-right asymmetry and male infertility [18, 34, 35]. The mutational prevalence of DNAH5 is currently known in a total of 134 PCD families [18, 35]. In $38(28 \%)$ of these 134 PCD families, DNAH5 mutations were detected; the mutation detection rate was even higher (49\%) when only PCD families with documented ODA defects (32 out of 65 PCD families) were considered. Exons 34, 50, 63, 76 and 77 harbour DNAH5 mutations in $53 \%$ of the analysed PCD families, with c.10815delT (see table 1) as founder mutation in the USA [35]. Mutations often resulted in a complete absence of ODAs in respiratory cilia, and rarely in shortened stubby ODA, in most transmission electron microscopy (EM) sections [36]. Respiratory cilia were either immotile or showed some residual flickery movement.

\section{DNAl1}

DNAI1 is a human axonemal dynein intermediate chain 1 gene located on chromosome 9p21-p13, and is an orthologue of the Chlamydomonas ODA 78-kDa intermediate chain (IC78). Mutations in this gene have been observed in PCD patients $[17,37-40]$. This gene was identified based on a candidate gene approach since Chlamydomonas algae lacking IC78 lost 70\% of their motility and were slow swimming [17, 41]. Combining all DNAI1 mutational studies, a total of 330 unrelated patients have been analysed to date; $25(7.5 \%)$ patients had DNAI1 mutations. A total of $\sim 30 \%$ of the mutant alleles resided in the mutation cluster (exons 13, 16 and 17), whereas $\sim 60 \%$ of the mutant alleles showed the IVS1 + 3insT (see table 1) founder mutation. Respiratory cilia are either immotile or show a severely reduced beating frequency.

\section{DNAH11}

Mutations of the DNAH11 gene encoding the orthologue of the Chlamydomonas $\beta$-heavy chain were identified in two families with randomisation of left-right body asymmetry, situs inversus and respiratory phenotype, whereas EM revealed normal respiratory cilia axonemes without any obvious ultrastructural dynein arm defects [18, 42]. High-speed videomicroscopy revealed a hyperkinetic dyskinetic ciliary beating pattern in the affected members of the second reported family.

\section{TXNDC3}

TXNDC3 represents the human orthologue of the sea urchin intermediate chain 1 gene that encodes a component of sperm ODAs [18, 43]. In 47 patients with either functional or ultrastructural ciliary abnormalities, screening of the 18 TXNDC3 exons revealed recessive sequence variants only in one female child [18]. The child had chronic respiratory disease 
TABLE 1 Description of the genes involved in primary ciliary dyskinesia (PCD)

\begin{tabular}{|c|c|c|c|c|c|c|}
\hline Gene & Locus & Defective structure & Exon & Hot spot & Founder mutation & Phenotype \\
\hline DNAH5 & $5 p 15$ & ODA & $79+1$ & Exons $34,50,63,76,77$ & c. 10815 delT & $\mathrm{PCD}+\mathrm{KS}$ \\
\hline DNAH11 & 7p15.3-21 & Normal & 82 & Not known & Not known & $\mathrm{PCD}+\mathrm{KS}$ \\
\hline TXNDC3 & $7 p 14.1$ & ODA & 18 & Not known & Not known & KS \\
\hline DNAI2 & $17 q 25.1$ & ODA & 14 & Not known & Not known & $\mathrm{PCD}+\mathrm{KS}$ \\
\hline OFD1 & Xp22 & Not known & 23 & Not known & Not known & PCD with mental retardation \\
\hline RSPH9 & $6 \mathrm{p} 21$ & $\mathrm{CP}$ & 5 & Exon 5 & c.801_803delGAA & PCD \\
\hline RSPH4A & $6 q 22$ & $\mathrm{CP}$ & 6 & Not known & Not known & PCD \\
\hline
\end{tabular}

DNAH5: dynein, axonemal, heavy chain 5 gene; DNAl1: dynein, axonemal, intermediate chain 1 gene; DNAH11: dynein, axonemal, heavy chain 11 gene; TXNDC3 thioredoxin domain containing 3 (spermatozoa) gene; DNAI2: dynein, axonemal, intermediate chain 2 gene; KTU: chromosome 14 open reading frame 104 gene; RPGR retinitis pigmentosa guanosine triphosphatase regulator gene; OFD1: oral-facial-digital syndrome 1 gene; RSPH9: radial spoke head 9 homologue (Chlamydomonas) gene; RSPH4A: radial spoke head 4 homologue $\mathrm{A}$ (Chlamydomonas) gene; ODA: outer dynein arm; IDA: inner dynein arm; CP: central pair; C.: cDNA sequence; del: deletion; T: thymidine; IVS: intervening sequence; ins: insertion; G: guanine; A: adenine; KS: Kartagener's syndrome.

and situs ambiguus. The ciliary beat frequency appeared normal, and transmission EM revealed that $66 \%$ of the respiratory cilia had shortened or absent ODAs. The disease probably resulted from the unusual combination of a nonsense mutation and a common intronic variant found in $1 \%$ of control chromosomes.

\section{DNAI2}

DNAI2 is the human orthologue of the Chlamydomonas intermediate ODA IC69 (also known as IC2) gene [16]. Mutations in this gene have been observed in three families with Kartagener's syndrome, PCD and ODA defects [15]. The involvement of DNAI2 in PCD/Kartagener's syndrome was identified applying a positional and functional candidate-gene approach. Respiratory cilia were either immotile or showed only flickery residual movement.

\section{KTU}

$K T U$ was first identified in a medaka fish mutant, and found to be mutated in two PCD families with both ODA and inner dynein arm (IDA) deficiency [21]. This protein is involved in the pre-assembly of dynein arm complexes in the cytoplasm before intraflagellar transport carries them to the ciliary compartment. Respiratory cilia and sperm tails are immotile.

\section{RSPH4A and RSPH9}

Mutations within radial spoke head genes have been identified in a few families affected with PCD with associated central pair abnormalities [22]. Patients had no situs inversus. In the patients with RSPH4A mutations, the central pair was completely absent. Interestingly, in patients with RSPH9 mutations, the central pair was only intermittently absent. This defect was not present in all of those affected, making diagnosis of this PCD variant by EM challenging. All of the affected had an aberrant circular beating pattern, highlighting the importance of highspeed videomicroscopy.

\section{CLINICAL ASPECTS OF PCD}

Children with PCD often have a clinical history of lower airway disease, manifested in a chronic wet-sounding cough and, occasionally, wheeze or shortness of breath. In addition, virtually all subjects show evidence of chronic upper airway symptoms, such as chronic rhinitis (nasal discharge, episodic facial pain and anosmia). This may be confirmed by physical examination and/or sinus imaging. Ear symptoms (recurrent otitis media and glue ear) are a frequent complication that can require multiple interventions, including repeated courses of antibiotics. Diagnosis of PCD is frequently delayed [8], in part because patients present with symptoms (rhinitis, secretory otitis media, cough and recurrent bronchitis) that are common in healthy children [2]. In table 2, the clinical aspects of PCD are displayed by various age groups. A positive family history of PCD is an indication for performing diagnostics, since this accounted for $10 \%$ of cases in one series [8]. Siblings of probands should also have PCD excluded.

General paediatricians must be alert to this condition and take a careful focused history. Although there is no proven evidence that early diagnosis is beneficial, there is at least suggestive evidence in the literature and a consensus amongst those caring for patients with PCD. In one case series, bronchiectasis on diagnosis was only seen in those diagnosed aged $>4$ yrs [8], and, in another, lung function on diagnosis was worse in those diagnosed as adults [9], suggesting that early diagnosis is beneficial.

\section{$P C D$ as an associated diagnosis}

In addition to the above, we recommend that PCD should be at least considered when the following diagnoses are made, particularly if there is a family history of more than one of these conditions or the patient has other features of PCD [57, 58]: 1) complex congenital heart disease, especially with disorders of laterality [59], such as atrial isomerism, transposition of the great vessels, double-outlet right ventricle, 
TABLE 2 Antenatal, neonatal, childhood, adolescent and adult presentation of symptoms

Presentation of symptoms

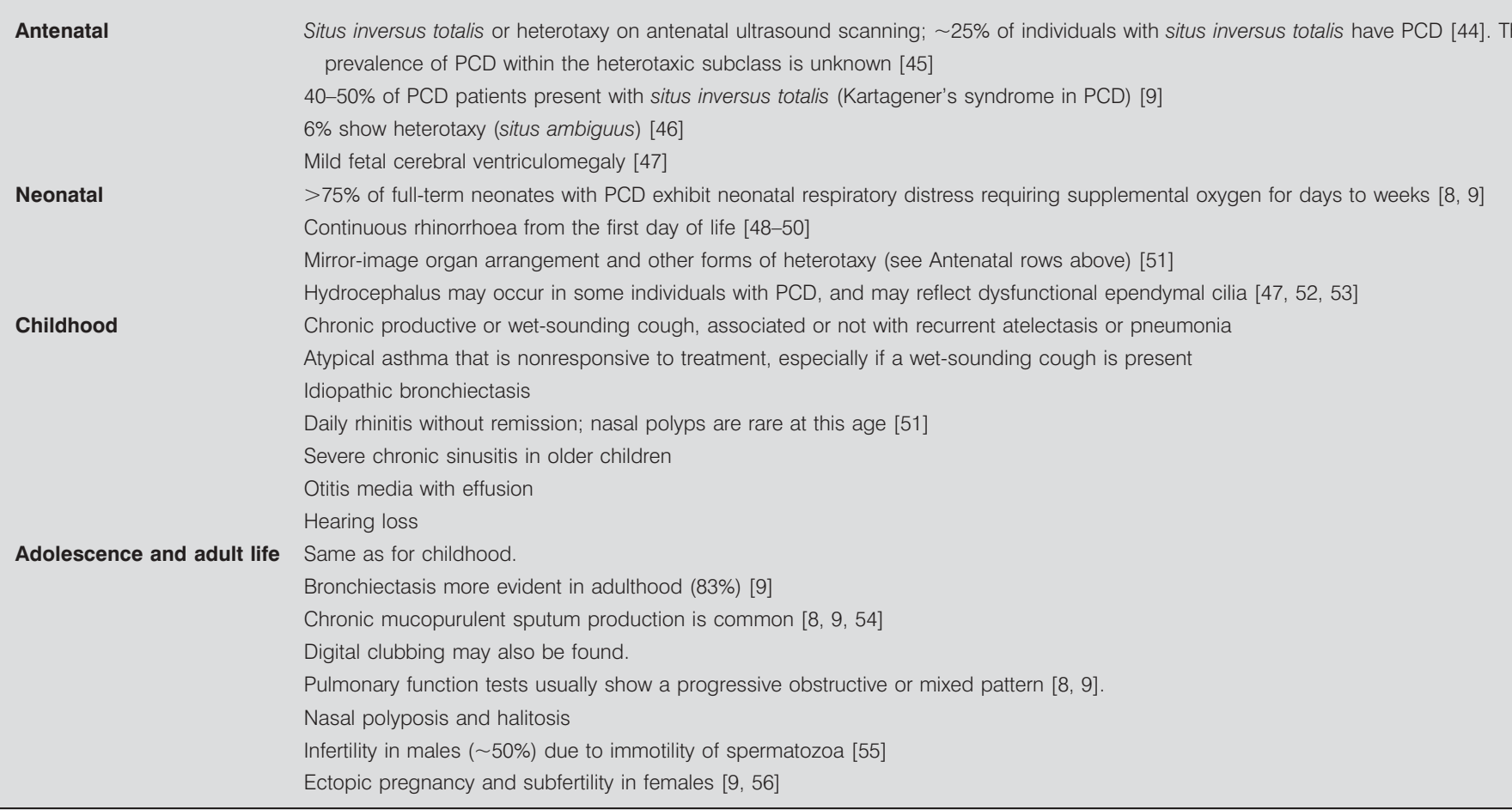

PCD: primary ciliary dyskinesia

anomalous venous return, interrupted inferior vena cava and bilateral superior vena cava [44]; 2) asplenia (predominant bilateral right-sidedness (right isomerism)) or polysplenia (predominant bilateral left-sidedness (left isomerism)) [60, 61], present in at least $6 \%$ of individuals with PCD [62]; 3) polycystic kidney or liver disease $[2,58,62] ; 4)$ hydrocephalus $[2,58,62]$; 5) biliary atresia $[2,62]$; 6) severe oesophageal disease (oesophageal atresia and severe reflux) [59]; 7) retinal degeneration, including retinitis pigmentosa [30]; and 8) oralfacial-digital syndrome type 1 [31].

\section{Recommendations}

1) Children who are found at any age to have situs inversus totalis, or any heterotaxic syndrome, should have PCD excluded by appropriate tests. Level of evidence: high; benefit: substantial; strength of recommendation: strong.

2) Children who are found to have cerebral ventriculomegaly at any age, in the absence of an obvious cause, and, in particular, if there are other features suggestive of PCD, should probably have this diagnosis excluded. Level of evidence: low; benefit: small; strength of recommendation: weak.

3). Siblings of probands should have PCD excluded. Level of evidence: high; benefit: substantial; strength of recommendation: strong.

4) Babies with otherwise unexplained neonatal respiratory distress, particularly if there are other features of PCD, should have this diagnosis excluded. Level of evidence: high; benefit: substantial; strength of recommendation: strong.

5) Children with chronic productive cough, bronchiectasis of unknown cause or severe upper airway disease should be considered for diagnostic testing for PCD after other more common diagnoses have been excluded, particularly if there are other features of PCD. Level of evidence: expert opinion; benefit: substantial; strength of recommendation: strong.

6) Males with immotile sperm should be referred for diagnostic testing for PCD. Level of evidence: high; benefit: substantial; strength of recommendation: strong.

7) Females with recurrent ectopic pregnancy should be considered for referral for diagnostic testing, especially if there are other features of PCD. Level of evidence: low; benefit: small; strength of recommendation: weak.

\section{DIAGNOSTIC TESTING}

The diagnosis of PCD should be based on the presence of a typical clinical phenotype and appropriate diagnostic testing. PCD is a rare disease, and diagnostic analysis and interpretation are difficult. Diagnosis should, therefore, be confirmed in a specialist centre. The clinical history and clinical observation are pivotal to diagnosis and extreme caution should be exercised in making a diagnosis if the clinical symptoms do not fit. Inflammation and infection can produce secondary ciliary defects, which may result in a misdiagnosis of PCD. If in doubt, repeat brushings should be performed following 
treatment of infection and inflammation. New phenotypes of PCD are still being discovered, and this will be aided by further developments in diagnostic testing $[42,63]$.

\section{Screening tests}

Screening tests may precede formal ciliary function analysis, thereby reducing the number of referrals for ciliary analysis. These screening tests may prevent some patients from requiring nasal biopsy/brushing, but do not obviate the need for specialist equipment and personnel.

\section{Nasal nitric oxide measurement}

A number of studies have shown that levels of exhaled nitric oxide, and particularly nasal NO, are very low in $\operatorname{PCD}[9,51,64$, 65]. A high or normal nasal NO level can help to exclude PCD, particularly in those in whom the history is not classical, but it should be noted that a few patients with PCD may have levels within the normal range [64]. A low measurement is not diagnostic of PCD, with low levels occurring in other conditions, including $\mathrm{CF}$, panbronchiolitis, nasal blockage and nasal polyposis. Confirmation of the diagnosis of PCD will, therefore, always require further diagnostic tests. Efforts are being made to standardise nasal NO measurements in all age groups in order to permit comparison between studies [66].

\section{The saccharin test}

The saccharin test permits a gross assessment of mucociliary function and is the only screening test that is widely available outside of specialised respiratory centres. A microtablet of saccharin is placed on the inferior turbinate and the time taken for the subject to taste it is recorded, having previously ensured that they can taste saccharin. This test is difficult to perform and unreliable in children aged $<12$ yrs. Cases with dyskinetically beating cilia can be missed [67].

\section{Radioaerosol mucociliary clearance tests}

Investigation of nasal and pulmonary mucociliary clearance by use of a radioactive tracer has been widely performed over the past 25 yrs [68-71]. However, studies on mucociliary clearance in patients with PCD are sparse [72-76]. Nasal mucociliary clearance can be used as a screening tool for PCD, even in infants. The sensitivity is high, but specificity low, and this method is, therefore, mainly suited for exclusion of PCD [75, 77]. Pulmonary radioaerosol mucociliary clearance (PRMC) was found to be a useful functional test in one study of assessment of mucociliary clearance in the lower airways. PRMC can be used in children from the age of 5 yrs. Both nasal mucociliary clearance and PRMC are supplementary tests in the armamentarium of PCD work-up testing since neither of the tests are diagnostic of PCD.

\section{Recommendations}

8) Measurement of nasal NO levels should be used as a screening test for patients aged $>5$ yrs suspected of having PCD; centres using nasal NO measurements as a screening test for PCD should generate their own normal reference values. Level of evidence: intermediate; benefit: small; strength of recommendation: strong.

9) The saccharin test should not be used in children. Level of evidence: intermediate; benefit: small; strength of recommendation: strong.
10) There is insufficient clinical experience of the use of PRMC in children to recommend its routine use in practice. Level of evidence: intermediate; benefit: small; strength of recommendation: strong.

\section{Diagnostic tests}

Diagnosis of PCD requires analysis of ciliate epithelial cells in order to assess function and ultrastructure. Further investigations, e.g. following primary cell culture, may aid diagnosis. There is no single gold standard test, and diagnosis should be made in a specialist centre following review of the clinical history and screening test results alongside these specific ciliary tests.

\section{Obtaining a sample of ciliate cells}

\section{Nasal brushing}

Ciliate epithelium is easily obtained by simple nasal brushing using a bronchoscopic brush. This only takes $2-3 \mathrm{~s}$, and, in preschool children, rarely requires anaesthesia or sedation. Patients should be free of an acute upper respiratory tract infection for 4-6 weeks. This helps to minimise poorly ciliate samples or secondary dyskinesia, which may complicate the analysis. In some centres curettage of nasal epithelium is used to obtain ciliate tissue.

\section{Bronchoscopic samples}

Respiratory epithelial cells may also be obtained from the bronchi using a bronchoscopic brush. In a review on flexible endoscopy of paediatric airways, biopsy by forceps is also reported as a method of collecting samples [78].

\section{Analysis of ciliary function and structure}

The Task Force Committee agrees that a combined approach to diagnostic testing of biopsy material is required in order to ensure that diagnostic errors are avoided. The Committee recommends the following key diagnostic techniques: ciliary beat pattern and frequency analysis using video recording; and EM analysis.

\section{Ciliary beat pattern and frequency analysis}

Analysis of ciliary beat pattern using a slow-motion-replay videotape recorder and a digital high-speed video camera is recommended as part of the diagnostic testing for PCD. Ciliate samples at $37^{\circ} \mathrm{C}$ are observed using a $100 \times$ objective. A digital high-speed video camera mounted on a conventional microscope permits recording of $>500$ frames $\cdot \mathrm{s}^{-1}$. These are played back in slow motion, allowing ciliary beat pattern to be assessed. A permanent recording can be made for audit purposes, and beat frequency can also be measured by directly observing the beating cilia in slow motion. In PCD, all of the cilia are seen to be dyskinetic on slow-motion replay. Analysis also permits measurement of ciliary beat frequency. Specific beat patterns have been shown to be related to particular ultrastructural defects [79-81]. This analysis is particularly useful in identifying patients who have ciliary dyskinesia due to an ultrastructural defect for which beat frequency is normal, e.g. in those with a central microtubular defect, such as ciliary transposition or central microtubular agenesis [63]. A major advantage is that videos may be stored as a permanent record, permitting reassessment if the clinical picture changes. 
Until the 1990s, prior to advances in high-speed video analysis, analysis of ciliary beat frequency without assessment of beat pattern was common. When the beat frequency is low, suspicion of PCD is high. It had been recommended that, if the ciliary beat frequency were above a certain threshold, further tests such as EM were not indicated. However, in the experience of some ciliary diagnostic centres, using ciliary beat frequency readings to reject the diagnosis of PCD results in 10$15 \%$ of patients with the disease being missed (data not shown), since they have beat pattern abnormalities despite normal beat frequency.

\section{Electron microscopy}

EM is important in the diagnosis of PCD, and is always performed when there is any suspicion of the diagnosis. However, specialist knowledge is required in order to interpret the various ultrastructural defects responsible for PCD [82-85], and it is acknowledged that ultrastructural analysis has limitations. IDA defects, in particular, are difficult to determine since they are less electron dense and less frequent along the ciliary axoneme. In addition, it has been shown that dynein motor protein composition varies along the ciliary length, meaning that ultrastructural defects can be missed using EM, depending upon the site of the ciliary cross-section [34]. Obtention of samples that do not have significant secondary damage can be difficult. This may lead to erroneous reports of new cases of PCD [83]. Various methods to improve analysis of EM images have been suggested [86]. Some patients with PCD may not have an obvious ultrastructural defect [42]; however, normal ciliary ultrastructure should always prompt a full diagnostic review.

\section{Other techniques assisting diagnosis}

\section{Cell culture}

The use of cell culture to improve diagnostic certainty in PCD has been defined by JORISSEN et al. [87]. Cell culture with redifferentiation of the ciliate epithelium is a highly specialised method and its main benefit is based on reduction of the secondary damage seen in the original sample that can mimic PCD. It is mostly used to reduce false positive diagnoses in patients with secondary ciliary dysfunction, and to confirm less common phenotypes, such as ciliary disorientation, ciliary aplasia, central microtubular agenesis and IDA defects. Occasionally, when the original biopsy sample has no observable cilia, culture of the cells permits differentiation into a ciliate phenotype that allows diagnostic testing. Cell culture is likely to play an increasing role in the evaluation of new phenotypes of PCD.

\section{Analysis of dynein protein localisation}

Detection and intracellular localisation of DNAH5 by immunofluorescence microscopy (IFM) may also help in the clinical diagnosis of PCD. This method has been developed and is routinely used at the University Hospital Freiburg (Freiburg, Germany) [34, 35, 88]. It has been shown that IFM can be used to identify ODA defects, including regional defects within the ciliary shaft $[34,35]$. In a blinded study, IFM confirmed an ODA defect in all PCD patients with an ultrastructural ODA defect documented by transmission EM $(n=16)$ [34]. Four of these patients carried DNAH5 and one DNAI1 mutations. In control samples ( $\mathrm{n}=10$ healthy controls; $\mathrm{n}=7$ disease controls, i.e. $\mathrm{CF})$,
DNAH5 localisation was always normal. The usefulness of IFM was confirmed in a later study in which all samples from PCD patients with DNAH5 mutations $(n=8)$ showed abnormal DNAH5 staining using IFM [35]. In five of these eight samples, EM was also performed and confirmed an ODA defect. In addition, the IFM method remains unaltered by secondary ciliary abnormalities [88]. Recent work has also shown that antibody-based techniques can diagnose not only ODA but also IDA abnormalities caused by KTU mutations in PCD [21]. In the future, it may be possible to develop a panel of antibodies directed towards multiple ciliary proteins that may enable screening of a wide variety of respiratory epithelial samples.

\section{Genetic analysis}

The genetic basis of PCD is progressively being unravelled. It is complicated by the multiple existing phenotypes and new emerging phenotypes of the disease [83]. Although genetic testing for some cases of PCD is possible, as described above, the Task Force Committee does not recommend it as part of initial diagnostic testing. After a clinical diagnosis has been ascertained, genetic testing may be directed according to the specific PCD variant (i.e. DNAH5 and DNAI1 testing in PCD patients with ODA defects or DNAH11 testing in a special functional defect).

PCD is likely to include a small number of milder phenotypes that may be manifest in subtle or no apparent structural defects and ciliary dysfunction. Identifying these defects and their clinical implications in diagnostic testing is an area for future research.

\section{Recommendations}

11) Ciliary beat pattern and frequency analysis using video recording and EM analysis as key diagnostic techniques should be used to ensure diagnosis. Level of evidence: high; benefit: substantial; strength of recommendation: strong.

12) Genetic testing can play a role in the more profound evaluation of PCD, but it is not recommended as part of initial diagnostic testing. Genetic testing should be effectuated only in cases in whom mutations are more likely to be found, depending upon the specific PCD variant. Level of evidence: expert opinion; benefit: substantial; strength of recommendation: weak.

13) If diagnosis is inconclusive or in doubt or if there is a strong suspicion of a rare PCD phenotype, repeated brush samples should be obtained for further diagnosis. Level of evidence: expert opinion; benefit: substantial; strength of recommendation: strong.

14) If diagnosis is inconclusive or in doubt or if there is a strong suspicion of a rare PCD phenotype, culture of ciliary brushings should be considered. Level of evidence: expert opinion; benefit: substantial; strength of recommendation: strong.

15) Negative ultrastructural analytical results using EM does not exclude a diagnosis of PCD, and, if there is a strong suspicion, further analyses should be carried out.

16) Patients in whom suspicion of PCD remains strong, and who have previously been screened for PCD using beat frequency assessment alone, should have their diagnosis reconsidered. 


\section{RESPIRATORY TREATMENT}

As with all chronic respiratory diseases, the aim of therapy for PCD is to restore or maintain normal lung function as far as is possible, based on early detection and vigorous treatment of complications. There are no randomised trials of PCD treatment, and, consequently, all treatment recommendations are based on a very low level evidence, or extrapolated from CF guidelines. However, CF has a different pathophysiology, and, therefore, responses to treatments may well be different (e.g. the effectiveness of recombinant human (rh) DNase inhalation in CF and nonCF bronchiectasis differs considerably [89, 90]). Hence it is unsatisfactory to extrapolate from $\mathrm{CF}$ to PCD treatment.

Given the current low levels of evidence, the Task Force Committee recommends that the clinician be flexible and ready to trial new therapies if a child is not doing well, but, equally importantly, ready to discontinue therapies that are not working.

Respiratory treatment involves aggressive treatment of upper and lower airway infections and airway clearance by combinations of physiotherapy and physical exercise. As with CF patients, it is likely that the best results will be obtained if treatment is in an experienced centre caring for a sufficient number of patients. There is no evidence to positively state how many patients such a centre needs to oversee, but, by analogy with CF (according to prevalence), $\geqslant 10-15$ probably need to be under follow-up. However, in parts of Europe, geographical factors may make this impossible.

\section{Antibiotics}

Regular ( $\geqslant 3$-monthly) culture of sputum or cough swabs should be performed. Airway infection with Haemophilus influenzae, Staphylococcus aureus and Streptococcus pneumoniae frequently occur, but Pseudomonas aeruginosa and nontuberculous mycobacteria have also been reported, usually in adults [9]. There is no evidence to recommend the use of prophylactic oral antibiotics in all patients, although this is used in some centres. However, if repeated courses of oral antibiotics are required, prophylaxis should be considered. High-dose oral antibiotics are recommended at the first sign of worsening respiratory symptoms or deterioration in lung function. Where possible, antibiotics should be chosen on the basis of sputum or cough-swab culture and sensitivity. Occasionally bronchoalveolar lavage may be necessary to obtain adequate specimens in non-sputum-producing children.

There are no data on the role of intravenous antibiotics in PCD. Empirically, if persistent respiratory symptoms do not respond to oral antibiotics, then intravenous therapy is given. A regular programme of 3-monthly intravenous therapies should be considered in patients who are not doing well. However, there are no controlled trials of this approach in PCD. If $P$. aeruginosa is isolated, most clinicians would prescribe an eradication regimen similar to those used in $\mathrm{CF}$, and, for established chronic infection with this organism, long-term nebulised antipseudomonal antibiotics are considered, but evidence of efficacy has yet to be gathered in PCD patients [91-93].

\section{Other inhaled medications}

There is even less evidence for other therapies. Regular bronchodilator use does not lead to worsening airway reactivity, but they are not particularly effective [94]. The role of nebulised rhDNase (Pulmozyme ${ }^{\mathrm{TM}}$; Genentech, San Francisco, CA, USA) in PCD patients remains unproven. However, anecdotally, some patients show an improvement in respiratory symptoms [95, 96]. Use of nebulised normal or hypertonic saline may theoretically be effective in increasing mucus clearance, but, unlike in $\mathrm{CF}$, there are no randomised controlled trials. $\mathrm{N}$-acetylcysteine has been shown not to be useful [97].

\section{Anti-inflammatory strategies}

There is considerable interest in the treatment of airway inflammation in CF, based on the hypothesis that inflammation is important in causing lung damage, but there are few studies on airway inflammation in children with PCD. Examination of spontaneously expectorated sputum reveals a predominantly neutrophilic profile similar to in CF [98]. Antiinflammatory strategies such as alternate-day prednisolone have been shown to be effective in CF [99], but need to be formally trialled in PCD before they could be recommended. There are no data on which to recommend or avoid inhaled corticosteroids; by analogy with CF [100], they are probably best avoided unless they can be shown to be of definite benefit in an individual patient.

\section{Airway clearance techniques}

Airway clearance techniques are prescribed widely in PCD patients, but there is no evidence for the efficacy of any one particular technique. Since cough clearance is intact, it could be speculated that techniques promoting this would be helpful. Physiotherapy varies with age, changing clinical state, and local expertise and resources. Efficacy trials of the various techniques available are urgently required in PCD patients.

The effect of physical exercise on airway clearance in PCD has not been fully investigated but may help sputum clearance. Exercise has been shown to be a better bronchodilator than a $\beta_{2}$-agonist in PCD [101]. Exercise is encouraged at all ages in order to promote general health and well-being. There are no data regarding whether or not inspiratory muscle training is useful in PCD.

\section{Environmental exposures}

Preventive counselling should include the avoidance of active and passive smoking, minimisation of exposure to respiratory pathogens, and minimisation of exposure to indoor and environmental pollutants. Cough suppressant medications must be avoided.

\section{Immunisations}

PCD patients should receive all childhood immunisations, as well as pneumococcal and influenza immunisation (the latter on a yearly basis), where these are not part of the normal childhood immunisation programme.

\section{Surgical procedures}

Complications of bronchiectasis and chronic lung disease become more prominent with age [9]. The role of lobectomy in advanced bronchiectasis is similar to that in other aetiologies, and can rarely be recommended. Although stabilisation or improvement of lung disease is expected with institution of modern treatment $[9,10]$, there are reports of 
PCD patients going on to lung transplantation, both living related [102] and cadaveric [9, 103, 104]. This underlines the fact that PCD is a serious condition, from which adults die, and that paediatricians are mandated to treat children aggressively to retard later deterioration.

\section{Recommendations}

17) Every effort should be made to make the diagnosis of PCD early and start treatment as soon as possible in order to prevent deterioration in lung function, and, in some cases, improve it. Level of evidence: expert opinion; benefit: substantial; strength of recommendation: strong.

18) Patients with PCD should be seen for either full or shared care in a centre specialising in the condition. Level of evidence: expert opinion; benefit: substantial; strength of recommendation: strong.

19) Airway clearance by combinations of physiotherapy and physical exercise should be encouraged and regularly prescribed in children with PCD. Level of evidence: moderate; benefit: substantial; strength of recommendation: strong.

20) Acute airway infection with $H$. influenzae, S. aureus, $S$. pneumoniae, $P$. aeruginosa and nontuberculous mycobacteria should be promptly cured with antibiotic treatment of adequate duration. The exact period of treatment varies with the infecting organism. Level of evidence: low; benefit: substantial; strength of recommendation: strong.

21) Long-term use of nebulised anti-pseudomonas antibiotics in patients chronically infected with $P$. aeruginosa should be considered in order to reduce exacerbations. Level of evidence: expert opinion: benefit: substantial; strength of recommendation: weak.

22) Prophylactic oral antibiotics should not be given to all PCD patients, but should be considered if repeated courses of oral antibiotics are required. Level of evidence: expert opinion; benefit: conflicting; strength of recommendation: weak.

23) High-dose oral antibiotics should be prescribed at the first sign of worsening respiratory symptoms or deterioration in lung function. If persistent respiratory symptoms do not respond to oral antibiotics, then intravenous therapy should be given. Level of evidence: expert opinion; benefit: substantial; strength of recommendation: strong.

24) PCD patients with true wheezing or asthma should be treated according to asthma and wheezing guidelines. Documentation of reversible airflow obstruction should be performed using age-appropriate techniques. Inhaled bronchodilator therapy should not be given to all patients. Level of evidence: low; benefit: conflicting; strength of recommendation: weak.

25) The use of nebulised rhDNase (Pulmozyme ${ }^{\mathrm{TM}}$ ) should possibly be considered in selected PCD patients. Level of evidence: low; benefit: conflicting; strength of recommendation: weak.

26) The use of nebulised normal or hypertonic saline should possibly be considered in order to increase mucus clearance. Level of evidence: low; benefit: conflicting; strength of recommendation: weak.
27) $N$-acetylcysteine should not be used. Level of evidence: moderate; benefit: none; strength of recommendation: strong.

28) Anti-inflammatory strategies, such as alternate-day prednisolone or inhaled corticosteroids, should not be used. Level of evidence: low; benefit: none; strength of recommendation: strong.

29) All patients with PCD should receive all childhood immunisations, including pneumococcal and influenza immunisation. Level of evidence: low; benefit: substantial; strength of recommendation: strong.

30) Passive and active smoking should be firmly discouraged. Level of evidence: expert opinion; benefit: substantial; strength of recommendation: strong.

31) Reduction of exposure to environmental pollutants should encouraged. Level of evidence: low; benefit: intermediate; strength of recommendation: weak.

\section{EAR, NOSE AND THROAT PROBLEMS IN PCD}

ENT symptoms in children, in combination with respiratory symptoms and the underlying bronchiectasis, make the diagnosis of PCD more feasible. In children affected by PCD, the respiratory epithelium in the nasopharynx, middle ear, paranasal sinuses and conducting airways (including the nasal pharynx, larynx, trachea, bronchi and bronchioles), which is normally lined with ciliate pseudostratified columnar epithelium, is dysfunctional and, therefore, alters mucociliary clearance. Ear-related problems are frequently seen in children with mucociliary clearance dysfunction, but nasal and paranasal sinus-related symptoms can also be found [49].

More than $85 \%$ of the children have chronic and sometimes severe otitis media with effusion. Most of them improve spontaneously by the age of 13 yrs [105]. The accumulation of mucus in the Eustachian tube causes conductive hearing loss that varies over time.

Treatment of acute middle ear infections requires prompt use of antibiotics. Otitis media with effusion is usually managed conservatively, with regular audiological assessment, hearing aids and hearing therapy, since treatment with ventilation tubes (grommets) often results in prolonged and offensive otorrhoea $[8,51,105,106]$.

Nasal secretions in children with PCD are regularly abundant, watery to mucoid, purulent during infections, and transported by gravity or airflow because of the absence of mucociliary clearance [107]. Typically described by the parents as a common but prolonged cold, chronic rhinitis can remain present from the neonatal period $[2,108]$. The severity is not correlated to ultrastructural defects.

In PCD, there is underdevelopment of the frontal and sphenoidal sinuses. Nasal polyps may be found in up to $18 \%$ of the patients $[54,109]$.

Clearance of nasal mucus is important, even if there is no role for mucolytic agents [110]. Saline nasal douches, and sometimes anticholinergics, may (anecdotally) be helpful. Recurrent acute or chronic sinusitis is rare, but adequate and prolonged antibiotic treatment is required; sometimes, recurrent infections can require endoscopic sinus surgery [108, 110-112]. 


\section{Recommendations}

32) The use of ventilation tubes (grommets) should be avoided where possible. Level of evidence: low: benefit: substantial; strength of recommendation: strong.

\section{OTHER SYSTEMS}

Children affected by PCD are usually seen by respiratory physicians and ENT specialists, even if congenital anatomical heart variations and infertility may be present.

Males with PCD may be infertile due to impaired sperm motility since the flagella of the sperm and cilia often (but not always) have the same ultrastructural and functional defects. The sperm count is typically normal, but sperm are immotile or their motility is severely limited [55, 82]. In some reports, up to $50 \%$ of males with PCD are fertile [55]. Some females with PCD exhibit normal fertility, but others show impaired fertility and an increased risk of ectopic pregnancy because of impaired ciliary function in the oviduct [82].

There are several reports of the birth of healthy children following ovular intracytoplasmic sperm injection in the case of male infertility [113-115].

Rarer associations of PCD, such as congenital heart disease, have been described [59]. The management of these associated conditions is unchanged by coexistence with PCD; respiratory problems should be kept in mind when general anaesthesia is required.

\section{Recommendations}

33) In patients with (sub-) fertility or congenital cardiac anomalies and recurrent respiratory tract infection, PCD should be considered in the diagnostic work-up. Level of evidence: low; benefit: small; strength of recommendation: weak.

34) Seminal analysis is recommended in males with PCD so that accurate counselling about reproductive capability may be given. Level of evidence: high; benefit: substantial; strength of recommendation: strong.

\section{OUTPATIENT FOLLOW-UP}

By analogy with CF, PCD patients should be managed in specialised centres, in which they have regular access to respiratory paediatricians, audiology, ENT surgeons and respiratory physiotherapists. Some patients need access to clinical psychology and social work services. It is wise to establish links with specialists who are involved on a more occasional basis with PCD patients, e.g. speech therapists.

In addition to general paediatric care, each patient should make regular visits to a tertiary centre in order to check growth, lung function (including pulse oximetry) and hearing. Regular sputum or cough-swab cultures should be performed. Chest radiographs are probably relatively insensitive. Highresolution computed tomography of the lungs is used to define the extent of bronchiectasis, and can be used to monitor the progression of the disease. However, there is even less evidence that regular computed tomographic scans affect outcome in PCD than there is for $\mathrm{CF}$, and the potentially high lifetime cumulative radiation exposure should be seriously considered. Imaging of the upper airway is only indicated if it will help clinical decision making, e.g. to determine the need for endoscopic sinus surgery, and is not carried out on a routine basis. The child should have access to more sophisticated investigations, such as exercise and fitness-to-fly testing, as appropriate. The interval between visits is determined by the age and clinical condition of the patients and geographical factors. If the specialist centre is far removed from where the patient lives, a protocolised shared-care system, analogous to $\mathrm{CF}$, may be appropriate.

Virtually all children with PCD should survive into adult life. Therefore, in most countries in Europe, there is a need to organise transition services between paediatric and adult care. There are no data on how best to do this. By analogy with other chronic diseases, the following general principles seem reasonable: 1) transition should be a gradual process, and the idea of transition introduced early; 2) older children, and especially teenagers, should be encouraged to come in for the first part of the consultation without their parents, to encourage independence; 3 ) there should be flexibility in the timing of transition, but, in most countries, the age of transition will be in the range 16-18 yrs; 4) transition should be to an adult service with expertise in the management of PCD; and 5) the model of a joint clinic, in which the young adult is seen by both paediatrician and adult specialists and their teams prior to full transfer to the adult services, may be helpful.

\section{Recommendations}

35) A protocolised shared-care system is recommended in order to ensure close follow-up and prevent eventual lung damage. Level of evidence: fair; benefit: substantial; strength of recommendation: strong.

36) Regular sputum or cough-swab cultures should be performed based on clinic and hospital or local colonisation. Level of evidence: fair; benefit: substantial; strength of recommendation: strong.

\section{CONCLUSIONS AND NEXT STEPS}

The main conclusion of the present Task Force is the urgent need for further research into PCD. Most of the published data relating to $\mathrm{PCD}$ are observational and derived from small case series. The natural history of PCD, and how this might be altered by treatments, is virtually unknown. Therefore, most recommendations regarding diagnosis and treatment provided in the present consensus statement are based on low-tomoderate-level evidence. The Task Force Committee has stated that the following research areas are urgent: 1) studies on the natural history of PCD, including long-term outcome in adult life, spectrum and severity of clinical disease, functional limitations and quality of life in patients of different ages, based on large and representative patient samples; 2) further development of diagnostic techniques, in order to permit a sensitive, specific and practicable approach to diagnosis; 3 ) the setting up of an international database for PCD patients, to permit long-term multicentric observational and interventional studies; 4) high-quality randomised controlled multicentric trials to investigate the effect of different treatments on symptoms, lung function, quality of life and long-term progression of the disease; and 5) studies on genetic mutation and its correlation with certain PCD phenotypes are required 
in order to sustain the diagnosis of PCD and to make prenatal counselling possible in these families.

\section{SUPPORT STATEMENT}

The European Respiratory Society has supported meetings of the primary ciliary dyskinesia task force and helped to finance the meetings. C. Kuehni and M-P.F. Strippoli were funded by the Swiss National Science Foundation (Program for Social Medicine, Preventive and Epidemiological Research grants 3233-069348 and 3200-069349). H. Omran was funded by the German Research Foundation (grant DFG Om 6/4).

\section{STATEMENT OF INTEREST}

None declared.

\section{ACKNOWLEDGEMENTS}

The affiliations of the present authors are as follows. A. Barbato and D. Snijders: Dept of Paediatrics, University of Padua, Padua, Italy. T. Frischer: Dept of Paediatrics, University of Vienna, Vienna; and E. Eber: Respiratory and Allergic Disease Division, Paediatric Dept, Medical University of Graz, Graz (both Austria). C.E. Kuehni and M-P.F. Strippoli: Institute of Social and Preventive Medicine, University of Berne, Berne; and L. Bartoloni: Dept of Genetic Medicine and Development, University of Geneva Medical School, Geneva (both Switzerland). I. Azevedo: Dept of Paediatrics, Hospital São João, Porto, Portugal. G. Baktai: Paediatric Institute Svabhegy, Budapest, Hungary. A. Escribano: Paediatric Pneumology Unit, Dept of Paediatrics, Clinic University Hospital, University of Valencia, Valencia, Spain. E. Haarman: Dept of Paediatrics and Neonatology, Emma Children's Hospital Academic Medical Centre, Amsterdam, the Netherlands. B. Hesselmar: Dept of Paediatrics, Institute of Clinical Sciences, Sahlgrenska Academy of Gothenburg University, Gothenburg, Sweden. C. Hogg and A. Bush: Dept of Paediatric Respiratory Medicine, Royal Brompton Hospital, London; J. Lucas: Chest Medicine, Southampton University Hospitals NHS Trust, Southampton; and C. O'Callaghan: Division of Paediatrics, Dept of Infection, Immunity and Inflammation, University of Leicester and Leicester Children's Hospital, Leicester (all UK). M. Jorissen: Ear, Nose and Throat Dept, Head and Neck Surgery, University Hospitals Leuven, Leuven, Belgium. K.G. Nielsen: Paediatric Pulmonary Service and Cystic Fibrosis Centre, Dept of Paediatrics, Clinic I, Juliane Marie Centre, Copenhagen University Hospital, Rigshospitalet, Copenhagen, Denmark. H. Omran: Dept of Paediatrics and Adolescent Medicine, University Hospital Freiburg, Freiburg, Germany. P. Pohunek: Dept of Paediatrics, University Hospital Motol and $2^{\text {nd }}$ School of Medicine, Charles University, Prague, Czech Republic.

\section{REFERENCES}

1 O'Callaghan C, Chilvers M, Hogg C, et al. Diagnosing primary ciliary dyskinesia. Thorax 2007; 62: 656-657.

2 Bush A, Chodhari R, Collins N, et al. Primary ciliary dyskinesia: current state of the art. Arch Dis Child 2007; 92: 1136-1140.

3 Atkins D, Best D, Briss PA, et al. Grading quality of evidence and strength of recommendations. BMJ 2004; 328: 1490.

4 Torgersen J. Transportation of viscera bronchiectasis and nasal polyps, genetical analysis and contribution to the problem of constitution. Acta Radiol 1947; 38: 17-24.

5 Afzelius BA, Stenram U. Prevalence and genetics of immotile-cilia syndrome and left-handedness. Int J Dev Biol 2006; 50: 571-573.

6 Katsuhara K, Kawamoto S, Wakabayashi T, et al. Situs inversus totalis and Kartagener's syndrome in a Japanese population. Chest 1972; 61: 56-61.

7 Verra F, Escudier E, Bignon J, et al. Inherited factors in diffuse bronchiectasis in the adult: a prospective study. Eur Respir J 1991; 4: 937-944.
8 Coren ME, Meeks M, Morrison I, et al. Primary ciliary dyskinesia: age at diagnosis and symptom history. Acta Paediatr 2002; 91: 667-669.

9 Noone PG, Leigh MW, Sannuti A, et al. Primary ciliary dyskinesia: diagnostic and phenotypic features. Am J Respir Crit Care Med 2004; 169: 459-467.

10 Ellerman A, Bisgaard H. Longitudinal study of lung function in a cohort of primary ciliary dyskinesia. Eur Respir J 1997; 10 2376-2379.

11 Corkey CW, Levison H, Turner JA. The immotile cilia syndrome. A longitudinal survey. Am Rev Respir Dis 1981; 124: 544-548.

12 Hellinckx J, Demedts M, De Boeck K. Primary ciliary dyskinesia: evolution of pulmonary function. Eur J Pediatr 1998; 157: 422-426.

13 Afzelius BA. A human syndrome caused by immotile cilia. Science 1976; 193: 317-319.

14 Zariwala MA, Knowles MR, Omran H. Genetic defects in ciliary structure and function. Annu Rev Physiol 2007; 69: 423-450.

15 Loges NT, Olbrich H, Fenske L, et al. DNAI2 mutations cause primary ciliary dyskinesia with defects in the outer dynein arm. Am J Hum Genet 2008; 83: 547-558.

16 Pennarun G, Chapelin C, Escudier E, et al. The human dynein intermediate chain 2 gene (DNAI2): cloning, mapping, expression pattern, and evaluation as a candidate for primary ciliary dyskinesia. Hum Genet 2000; 107: 642-649.

17 Pennarun G, Escudier E, Chapelin C, et al. Loss-of-function mutations in a human gene related to Chlamydomonas reinhardtii dynein IC78 result in primary ciliary dyskinesia. Am J Hum Genet 1999; 65: 1508-1519.

18 Olbrich H, Häffner K, Kispert A, et al. Mutations in DNAH5 cause primary ciliary dyskinesia and randomization of left-right asymmetry. Nat Genet 2002; 30: 143-144.

19 Bartoloni L, Blouin JL, Pan Y, et al. Mutations in the DNAH11 (axonemal heavy chain dynein type 11) gene cause one form of situs inversus totalis and most likely primary ciliary dyskinesia. Proc Natl Acad Sci USA 2002; 99: 10282-10286.

20 Duriez B, Duquesnoy P, Escudier E, et al. A common variant in combination with a nonsense mutation in a member of the thioredoxin family causes primary ciliary dyskinesia. Proc Natl Acad Sci USA 2007; 104: 3336-3341.

21 Omran $\mathrm{H}$, Kobayashi D, Olbrich $\mathrm{H}$, et al. Ktu/PF13 is required for cytoplasmic pre-assembly of axonemal dyneins. Nature 2008; 456: 611-616.

22 Castleman VH, Romio L, Chodhari R, et al. Mutations in radial spoke head protein genes RSPH9 and RSPH4A cause primary ciliary dyskinesia with central-microtubular-pair abnormalities. Am J Hum Genet 2009; 84: 197-209.

23 Narayan D, Krishnan SN, Upender M, et al. Unusual inheritance of primary ciliary dyskinesia (Kartagener's syndrome). J Med Genet 1994; 31: 493-496.

24 van Dorp DB, Wright AF, Carothers AD, et al. A family with RP3 type of X-linked retinitis pigmentosa: an association with ciliary abnormalities. Hum Genet 1992; 88: 331-334.

25 Hong DH, Pawlyk BS, Adamian M, et al. A single, abbreviated RPGR-ORF15 variant reconstitutes RPGR function in vivo. Invest Ophthalmol Vis Sci 2005; 46: 435-441.

26 Iannaccone A, Breuer DK, Wang XF, et al. Clinical and immunohistochemical evidence for an $X$ linked retinitis pigmentosa syndrome with recurrent infections and hearing loss in association with an RPGR mutation. J Med Genet 2003; 40: e118.

27 Hong DH, Pawlyk B, Sokolov M, et al. RPGR isoforms in photoreceptor connecting cilia and the transitional zone of motile cilia. Invest Ophthalmol Vis Sci 2003; 44: 2413-2421.

28 Dry KL, Manson FD, Lennon A, et al. Identification of a 5' splice site mutation in the RPGR gene in a family with X-linked retinitis pigmentosa (RP3). Hum Mutat 1999; 13: 141-145. 
29 Zito I, Downes SM, Patel RJ, et al. RPGR mutation associated with retinitis pigmentosa, impaired hearing, and sinorespiratory infections. J Med Genet 2003; 40: 609-615.

30 Moore A, Escudier E, Roger G, et al. RPGR is mutated in patients with a complex $X$ linked phenotype combining primary ciliary dyskinesia and retinitis pigmentosa. J Med Genet 2006; 43: 326-333.

31 Budny B, Chen W, Omran H, et al. A novel X-linked recessive mental retardation syndrome comprising macrocephaly and ciliary dysfunction is allelic to oral-facial-digital type I syndrome. Hum Genet 2006; 120: 171-178.

32 Omran H, Häffner K, Völkel A, et al. Homozygosity mapping of a gene locus for primary ciliary dyskinesia on chromosome $5 p$ and identification of the heavy dynein chain DNAH5 as a candidate gene. Am J Respir Cell Mol Biol 2000; 23: 696-702.

33 Wilkerson CG, King SM, Witman GB. Molecular analysis of the $\gamma$ heavy chain of Chlamydomonas flagellar outer-arm dynein. J Cell Sci 1994; 107: 497-506.

34 Fliegauf $\mathrm{M}$, Olbrich $\mathrm{H}$, Horvath $\mathrm{J}$, et al. Mislocalization of DNAH5 and DNAH9 in respiratory cells from patients with primary ciliary dyskinesia. Am J Respir Crit Care Med 2005; 171: 1343-1349.

35 Hornef N, Olbrich $\mathrm{H}$, Horvath J, et al. DNAH5 mutations are a common cause of primary ciliary dyskinesia with outer dynein arm defects. Am J Respir Crit Care Med 2006; 174: 120-126.

36 Kispert A, Petry M, Olbrich H, et al. Genotype-phenotype correlations in PCD patients carrying DNAH5 mutations. Thorax 2003; 58: 552-554.

37 Guichard C, Harricane MC, Lafitte JJ, et al. Axonemal dynein intermediate-chain gene (DNAI1) mutations result in situs inversus and primary ciliary dyskinesia (Kartagener syndrome). Am J Hum Genet 2001; 68: 1030-1035.

38 Zariwala M, Noone PG, Sannuti A, et al. Germline mutations in an intermediate chain dynein cause primary ciliary dyskinesia. Am J Respir Cell Mol Biol 2001; 25: 577-583.

39 Zariwala MA, Leigh MW, Ceppa F, et al. Mutations of DNAI1 in primary ciliary dyskinesia: evidence of founder effect in a common mutation. Am J Respir Crit Care Med 2006; 174: 858-866.

40 Failly M, Saitta A, Muñoz A, et al. DNAI1 mutations explain only $2 \%$ of primary ciliary dykinesia. Respiration 2008; 76: 198-204.

41 Mitchell DR, Kang Y. Identification of oda6 as a Chlamydomonas dynein mutant by rescue with the wild-type gene. J Cell Biol 1991; 113: 835-842.

42 Schwabe GC, Hoffmann K, Loges NT, et al. Primary ciliary dyskinesia associated with normal axoneme ultrastructure is caused by DNAH11 mutations. Hum Mutat 2008; 29: 289-298.

43 Sadek CM, Jiménez A, Damdimopoulos AE, et al. Characterization of human thioredoxin-like 2. A novel microtubule-binding thioredoxin expressed predominantly in the cilia of lung airway epithelium and spermatid manchette and axoneme. J Biol Chem 2003; 278: 13133-13142.

44 Zhu L, Belmont JW, Ware SM. Genetics of human heterotaxias. Eur J Hum Genet 2006; 14: 17-25.

45 Brueckner M. Heterotaxia, congenital heart disease, and primary ciliary dyskinesia. Circulation 2007; 115: 2793-2795.

46 Kennedy MP, Omran H, Leigh MW, et al. Congenital heart disease and other heterotaxic defects in a large cohort of patients with primary ciliary dyskinesia. Circulation 2007; 115: 2814-2821.

47 Wessels MW, den Hollander NS, Willems PJ. Mild fetal cerebral ventriculomegaly as a prenatal sonographic marker for Kartagener syndrome. Prenat Diagn 2003; 23: 239-242.

48 Holzmann D, Felix H. Neonatal respiratory distress syndrome - a sign of primary ciliary dyskinesia? Eur J Pediatr 2000; 159: 857-860.

49 Ferkol T, Leigh M. Primary ciliary dyskinesia and newborn respiratory distress. Semin Perinatol 2006; 30: 335-340.

50 Hossain T, Kappelman MD, Perez-Atayde AR, et al. Primary ciliary dyskinesia as a cause of neonatal respiratory distress: implications for the neonatologist. J Perinatol 2003; 23: 684-687.
51 Bush A, Cole P, Hariri M, et al. Primary ciliary dyskinesia: diagnosis and standards of care. Eur Respir J 1998; 12: 982-988.

52 Eley L, Yates LM, Goodship JA. Cilia and disease. Curr Opin Genet Dev 2005; 15: 308-314.

53 Kosaki K, Ikeda K, Miyakoshi K, et al. Absent inner dynein arms in a fetus with familial hydrocephalus-situs abnormality. $A m \mathrm{~J}$ Med Genet A 2004; 129A: 308-311.

54 Leigh MW. Primary ciliary dyskinesia. Semin Respir Crit Care Med 2003; 24: 653-662.

55 Munro NC, Currie DC, Lindsay KS, et al. Fertility in men with primary ciliary dyskinesia presenting with respiratory infection. Thorax 1994; 49: 684-687.

56 Halbert SA, Patton DL, Zarutskie PW, et al. Function and structure of cilia in the fallopian tube of an infertile woman with Kartagener's syndrome. Hum Reprod 1997; 12: 55-58.

57 Ong AC, Wheatley DN. Polycystic kidney disease: the ciliary connection. Lancet 2003; 361: 774-776.

58 Badano JL, Mitsuma N, Beales PL, et al. The ciliopathies: an emerging class of human genetic disorders. Annu Rev Genomics Hum Genet 2006; 7: 125-148.

59 Gemou Engesaeth V, Warner JO, Bush A. New associations of primary ciliary dyskinesia syndrome. Pediatr Pulmonol 1993; 16 9-12.

60 Brueckner M. Cilia propel the embryo in the right direction. Am J Med Genet 2001; 101: 339-344.

61 Raman R, Al-Ali SY, Poole CA, et al. Isomerism of the right atrial appendages: clinical, anatomical, and microscopic study of a long surviving case with asplenia and ciliary abnormalities. Clin Anat 2003; 16: 269-276.

62 Bisgrove BW, Yost HJ. The roles of cilia in developmental disorders and disease. Development 2006; 133: 4131-4143.

63 Stannard W, Rutman A, Wallis C, et al. Central microtubular agenesis causing primary ciliary dyskinesia. Am J Respir Crit Care Med 2004; 169: 634-637.

64 Karadag B, James AJ, Gultekin E, et al. Nasal and lower airway level of nitric oxide in children with primary ciliary dyskinesia. Eur Respir J 1999; 13: 1402-1405.

65 Lundberg JO, Weitzberg E, Nordvall SL, et al. Primarily nasal origin of exhaled nitric oxide and absence in Kartagener's syndrome. Eur Respir J 1994; 7: 1501-1504.

66 American Thoracic Society., European Respiratory Society.: ATS/ERS recommendations for standardized procedures for the online and offline measurement of exhaled lower respiratory nitric oxide and nasal nitric oxide, 2005. Am J Respir Crit Care Med 2005; 171: 912-930.

67 Canciani M, Barlocco EG, Mastella G, et al. The saccharin method for testing mucociliary function in patients suspected of having primary ciliary dyskinesia. Pediatr Pulmonol 1988; 5: 210-214.

68 Yeates DB, Pitt BR, Spektor DM, et al. Coordination of mucociliary transport in human trachea and intrapulmonary airways. J Appl Physiol 1981; 51: 1057-1064.

69 Del Donno M, Pavia D, Agnew JE, et al. Variability and reproducibility in the measurement of tracheobronchial clearance in healthy subjects and patients with different obstructive lung diseases. Eur Respir J 1988; 1: 613-620.

70 Mortensen J, Lange P, Nyboe J, et al. Lung mucociliary clearance. Eur J Nucl Med 1994; 21: 953-961.

71 Mortensen J. Bronchoscintigraphy and pulmonary clearance of ${ }^{99 \mathrm{~m}}$ Tc-albumin colloid in the study of mucociliary clearance. Dan Med Bull 1998; 45: 195-209.

72 Camner P, Mossberg B, Afzelius BA. Measurements of tracheobronchial clearance in patients with immotile-cilia syndrome and its value in differential diagnosis. Eur J Respir Dis Suppl 1983; 127: 57-63.

73 Baum GL, Zwas ST, Katz I, et al. Mucociliary clearance from central airways in patients with excessive sputum production 
with and without primary ciliary dyskinesia. Chest 1990; 98: 608-612.

74 Svartengren K, Philipson K, Svartengren M, et al. Clearance in smaller airways of inhaled $6-\mu \mathrm{m}$ particles in subjects with immotile-cilia syndrome. Exp Lung Res 1995; 21: 667-682.

75 De Boeck K, Proesmans M, Mortelmans L, et al. Mucociliary transport using ${ }^{99 \mathrm{~m}} \mathrm{Tc}$-albumin colloid: a reliable screening test for primary ciliary dyskinesia. Thorax 2005; 60: 414-417.

76 Marthin JK, Mortensen J, Pressler T, et al. Pulmonary radioaerosol mucociliary clearance in diagnosis of primary ciliary dyskinesia. Chest 2007; 132: 966-976.

77 Armengot M, Escribano A, Carda C, et al. Clinical and ultrastructural correlations in nasal mucociliary function observed in children with recurrent airways infections. Int $J$ Pediatr Otorhinolaryngol 1995; 32: 143-151.

78 Midulla F, de Blic J, Barbato A, et al. Flexible endoscopy of paediatric airways. Eur Respir J 2003; 22: 698-708.

79 Chilvers MA, O'Callaghan C. Analysis of ciliary beat pattern and beat frequency using digital high speed imaging: comparison with the photomultiplier and photodiode methods. Thorax 2000; 55: 314-317.

80 Chilvers MA, Rutman A, O'Callaghan C. Ciliary beat pattern is associated with specific ultrastructural defects in primary ciliary dyskinesia. J Allergy Clin Immunol 2003; 112: 518-524.

81 Chilvers MA, Rutman A, O'Callaghan C. Functional analysis of cilia and ciliated epithelial ultrastructure in healthy children and young adults. Thorax 2003; 58: 333-338.

82 Afzelius BA. Cilia-related diseases. J Pathol 2004; 204: 470-477.

83 Ferkol T, Mitchinson H, O'Callaghan C, et al. Current issues in the basic mechanisms, pathophysiology, diagnosis and management of primary ciliary dyskinesia. In: Frey U., Gerritsen J., eds. Respiratory Diseases in Infants and Children. Eur Respir Mon 2006; 37: 291-313.

84 Scholey JM. Intraflagellar transport. Annu Rev Cell Dev Biol 2003; 19: 423-443.

85 Scholey JM. Intraflagellar transport motors in cilia: moving along the cell's antenna. J Cell Biol 2008; 180: 23-29.

86 Escudier E, Couprie M, Duriez B, et al. Computer-assisted analysis helps detect inner dynein arm abnormalities. Am J Respir Crit Care Med 2002; 166: 1257-1262.

87 Jorissen M, Willems T, Van der Schueren B, et al. Ultrastructural expression of primary ciliary dyskinesia after ciliogenesis in culture. Acta Otorhinolaryngol Belg 2000; 54: 343-356.

88 Olbrich H, Horváth J, Fekete A, et al. Axonemal localization of the dynein component DNAH5 is not altered in secondary ciliary dyskinesia. Ped Research 2006; 59: 418-422.

89 Fuchs HJ, Borowitz DS, Christiansen DH, et al. Effect of aerosolized recombinant human DNase on exacerbations of respiratory symptoms and on pulmonary function in patients with cystic fibrosis. N Engl J Med 1994; 331: 637-642.

90 Wills PJ, Wodehouse T, Corkery K, et al. Short-term recombinant human DNase in bronchiectasis. Effect on clinical state and in vitro sputum transportability. Am J Respir Crit Care Med 1996; 154: 413-417.

91 Hoiby N, Frederiksen B, Pressler T. Eradication of early Pseudomonas aeruginosa infection. J Cyst Fibros 2005; 4: 49-54.

92 Gibson RL, Emerson J, McNamara S, et al. Significant microbiological effect of inhaled tobramycin in young children with cystic fibrosis. Am J Respir Crit Care Med 2003; 167: 841-849.

93 Taccetti G, Campana S, Festini F, et al. Early eradication therapy against Pseudomonas aeruginosa in cystic fibrosis patients. Eur Respir J 2005; 26: 458-461.

94 Koh YY, Park Y, Jeong JH, et al. The effect of regular salbutamol on lung function and bronchial responsiveness in patients with primary ciliary dyskinesia. Chest 2000; 117: 427-433.
95 Desai M, Weller PH, Spencer DA. Clinical benefit from nebulized human recombinant DNase in Kartagener's syndrome. Pediatr Pulmonol 1995; 20: 307-308.

96 Ten Berge M, Brinkhorst G, Kroon AA, et al. DNase treatment in primary ciliary dyskinesia - assessment by nocturnal pulse oximetry. Pediatr Pulmonol 1999; 27: 59-61.

97 Stafanger G, Garne S, Howitz P, et al. The clinical effect and the effect on the ciliary motility of oral $\mathrm{N}$-acetylcysteine in patients with cystic fibrosis and primary ciliary dyskinesia. Eur Respir J 1988; 1: 161-167.

98 Zihlif N, Paraskakis E, Lex C, et al. Correlation between cough frequency and airway inflammation in children with primary ciliary dyskinesia. Pediatr Pulmonol 2005; 39: 551-557.

99 Eigen H, Rosenstein BJ, FitzSimmons S, et al. A multicenter study of alternate-day prednisone therapy in patients with cystic fibrosis. Cystic Fibrosis Foundation Prednisone Trial Group. J Pediatr 1995; 126: 515-523.

100 Balfour-Lynn IM, Lees B, Hall P, et al. Multicenter randomized controlled trial of withdrawal of inhaled corticosteroids in cystic fibrosis. Am J Respir Crit Care Med 2006; 173: 1356-1362.

101 Phillips GE, Thomas S, Heather S, et al. Airway response of children with primary ciliary dyskinesia to exercise and $\beta_{2-}$ agonist challenge. Eur Respir J 1998; 11: 1389-1391.

102 Date H, Yamashita M, Nagahiro I, et al. Living-donor lobar lung transplantation for primary ciliary dyskinesia. Ann Thorac Surg 2001; 71: 2008-2009.

103 Macchiarini P, Chapelier A, Vouhé P, et al. Double lung transplantation in situs inversus with Kartagener's syndrome. J Thorac Cardiovasc Surg 1994; 108: 86-91.

104 Graeter T, Schafers HJ, Wahlers T, et al. Lung transplantation in Kartagener's syndrome. J Heart Lung Transplant 1994; 13: 724-726.

105 Majithia A, Fong J, Hariri M, et al. Hearing outcomes in children with primary ciliary dyskinesia - a longitudinal study. Int $J$ Pediatr Otorhinolaryngol 2005; 69: 1061-1064.

106 Hadfield PJ, Rowe-Jones JM, Bush A, et al. Treatment of otitis media with effusion in children with primary ciliary dyskinesia. Clin Otolaryngol Allied Sci 1997; 22: 302-306.

107 Baroody FM. Mucociliary transport in chronic rhinosinusitis. Clin Allergy Immunol 2007; 20: 103-119.

108 Pedersen M, Mygind N. Rhinitis, sinusitis and otitis media in Kartagener's syndrome (primary ciliary dyskinesia). Clin Otolaryngol Allied Sci 1982; 7: 373-380.

109 Min YG, Shin JS, Choi SH, et al. Primary ciliary dyskinesia: ultrastructural defects and clinical features. Rhinology 1995; 33: 189-193.

110 Subcommittee on Management of Sinusitis and Committee on Quality ImprovementClinical practice guideline: management of sinusitis. Pediatrics 2001; 108: 798-808.

111 Mygind N, Pedersen M. Nose-, sinus- and ear-symptoms in 27 patients with primary ciliary dyskinesia. Eur J Respir Dis Suppl 1983; 127: 96-101.

112 Parsons DS, Greene BA. A treatment for primary ciliary dyskinesia: efficacy of functional endoscopic sinus surgery. Laryngoscope 1993; 103: 1269-1272.

113 Yildirim G, Ficicioglu C, Akcin O, et al. Can pentoxifylline improve the sperm motion and ICSI success in the primary ciliary dyskinesia? Arch Gynecol Obstet 2009; 279: 213-215.

114 Kaushal M, Baxi A. Birth after intracytoplasmic sperm injection with use of testicular sperm from men with Kartagener or immotile cilia syndrome. Fertil Steril 2007; 88: 497.e9-e11.

115 Westlander G, Barry M, Petrucco O, et al. Different fertilization rates between immotile testicular spermatozoa and immotile ejaculated spermatozoa for ICSI in men with Kartagener's syndrome: case reports. Hum Reprod 2003; 18: 1286-1288. 